\title{
Transarterial embolization through the infraorbital artery of the ethmoidal dural arteriovenous fistula causing recurrent epistaxis: illustrative case
}

\author{
Min-Yong Kwon, MD, Sae Min Kwon, MD, Chang-Hyun Kim, MD, and Chang-Young Lee, MD \\ Department of Neurosurgery, Keimyung University Dongsan Hospital, Keimyung University School of Medicine, Daegu, Republic of Korea
}

BACKGROUND This report describes an ethmoidal dural arteriovenous fistula (DAVF) presenting with the unusual symptom of recurrent epistaxis and successfully treated with selective transarterial embolization through the infraorbital artery (IOA), which is the first time this route was used to the best of the authors' knowledge, and reviews the literature focusing on the anatomical consideration of ethmoidal DAVFs causing epistaxis and its treatment approaches.

OBSERVATIONS A 70-year-old man experienced recurrent intractable epistaxis that bled like a faucet turned on. Cerebral angiography revealed an ethmoidal DAVF supplied by the left anterior ethmoidal artery, both sphenopalatine arteries, both IOAs, and the right angular artery, which drained directly into the frontal cortical veins with a tortuous arterialized ectasia. Microaneurysms around the fistulous location where multiple feeding arteries converge were demonstrated and considered the likely source of the epistaxis. The fistula was completely occluded using transarterial Onyx embolization through the IOA, a branch of the internal maxillary artery. No further epistaxis appeared.

LESSONS Although extremely rare, ethmoidal DAVFs should be included in the differential diagnosis of recurrent epistaxis. Ethmoidal DAVFs with bleeding sources in the ethmoid sinus and nasal cavity may cause epistaxis. It is important to properly diagnose and treat ethmoidal DAVFs presenting with epistaxis on the basis of a comprehensive anatomical understanding of extensive extracranial-extracranial and extracranial-intracranial anastomoses.

https://thejns.org/doi/abs/10.3171/CASE2123

KEYWORDS endovascular treatment; epistaxis; ethmoidal dural arteriovenous fistula; infraorbital artery; transarterial embolization

Ethmoidal dural arteriovenous fistulas (DAVFs) are rare but require active treatment because they present a high risk of intracranial (IC) hemorrhage at a rate of $62 \%-91 \% .^{1-4}$ However, it is difficult to detect this disease early on the basis of symptoms other than critical IC hemorrhage. This is because its symptoms, as in other DAVFs, can be nonspecific and varying, including headache, seizure, and visual impairment. ${ }^{5,6}$ In addition, decision-making on the treatment approach for this pathology has not been clearly established. Microsurgical and endovascular (both transarterial and transvenous) accesses have been suggested with their respective pros and cons. ${ }^{7-9}$
To date, very few case reports in the literature have described ethmoidal DAVFs presenting with epistaxis. ${ }^{10-13}$ However, its incidence, the anatomical relationship between ethmoidal DAVFs and epistaxis, and, accordingly, rational treatment approaches have not been investigated in depth. We report an ethmoidal DAVF presenting with the unusual symptom of recurrent epistaxis and successfully treated with selective transarterial embolization through the external carotid artery $(E C A)$ route and review the literature focusing on the anatomical consideration of ethmoidal DAVFs causing epistaxis and treatment approaches for such cases.

ABBREVIATIONS AA = angular artery; $\mathrm{AEA}=$ anterior ethmoidal artery; CCF = carotid cavernous fistula; DAVF = dural arteriovenous fistula; DSA = digital subtraction angiography; $E C=$ extracranial; $E C A=$ external carotid artery; IC = intracranial; IMA = internal maxillary artery; IOA = infraorbital artery; LEA = liquid embolic agent; MMA = middle meningeal artery; MRI = magnetic resonance imaging; OA = ophthalmic artery; SPA = sphenopalatine artery; SSS = superior sagittal sinus.

INCLUDE WHEN CITING Published April 26, 2021; DOI: 10.3171/CASE2123.

SUBMITTED January 11, 2021. ACCEPTED February 4, 2021.

(C) 2021 The authors, CC BY-NC-ND 4.0 (http://creativecommons.org/licenses/by-nc-nd/4.0/). 


\section{Illustrative Case}

A 70-year-old man presented at our medical emergency center with recurrent intractable epistaxis that did not resolve with nasal packing at a local medical clinic. He complained of copious nasal bleeding at a rate as if a faucet had been turned on and also suffered from the new onset of a mild bifrontal headache. The patient had no history of recent traumatic head injury, previous craniotomy, or thrombotic or infective disease. No neurological deficits were observed on physical examination, and blood tests for infection and vasculopathy were also unremarkable.

The emergency medical doctor suspected that the accompanying headache was a symptom of an IC lesion and referred the patient to our cerebrovascular department to check for any abnormal findings on brain radiological imaging. Tortuous venous ectasia in the right anterior cranial fossa was visualized on computed tomography angiography, and flow voids penetrating the ethmoid bone were observed on magnetic resonance imaging (MRI) of the brain, but IC hemorrhage was not seen at all (Fig. 1A).

Digital subtraction angiography (DSA) disclosed an ethmoidal DAVF showing an abnormal shunt on the cribriform plate of the ethmoid bone fed by multiple arterial feeders of the left anterior ethmoidal artery (AEA), both sphenopalatine arteries (SPAs), both infraorbital arteries (IOAs), and the right angular artery (AA). The fistula was Cognard type IV and drained directly into the right frontal cortical veins with tortuous arterialized ectasia, ultimately flowing
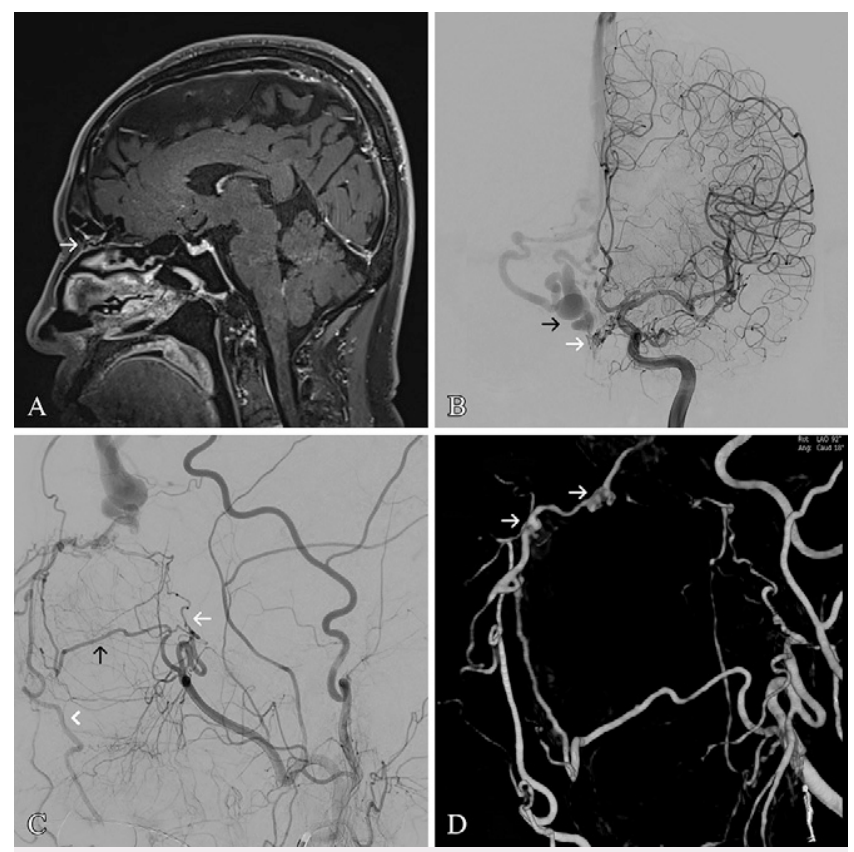

FIG. 1. A: Sagittal postgadolinium T1-weighted imaging shows flow voids penetrating the ethmoid bone (arrow). B: Anteroposterior angiography of left internal carotid artery shows the fistula fed by the left AEA (white arrow) and drained into the right frontal cortical veins (black arrow). C: Lateral angiography of the right ECA shows the fistula fed by the septal branches of the right SPA (white arrow), the right IOA (black arrow), and the right AA (arrowhead). D: Three-dimensional angiography of the right ECA demonstrates the microaneurysms around the fistulous location where multiple feeding arteries converge (arrows).

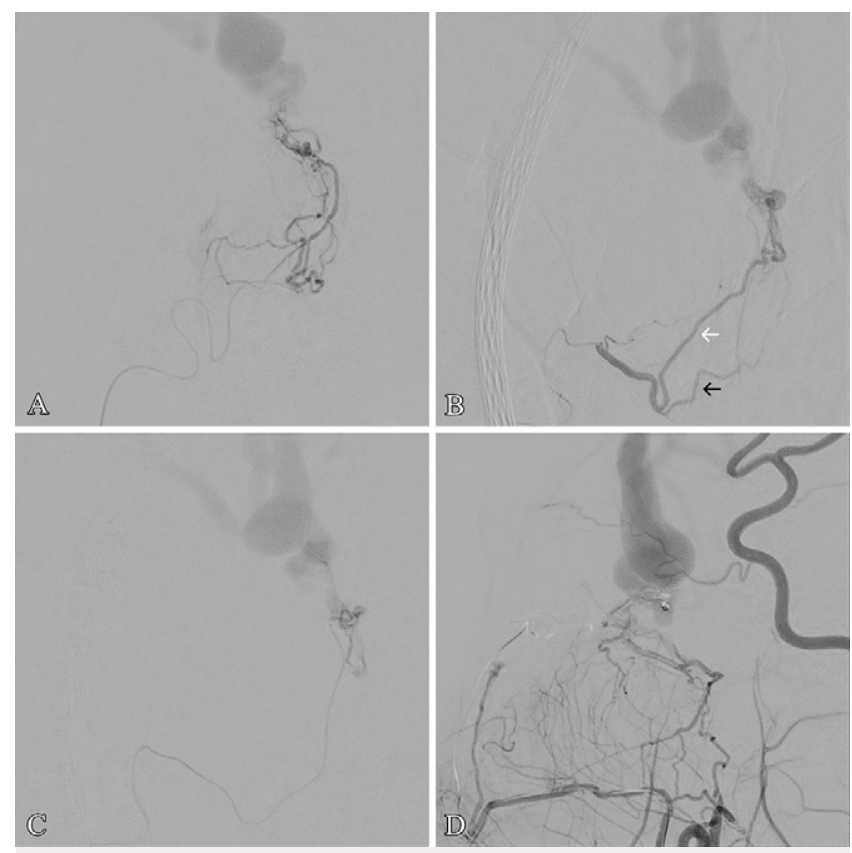

FIG. 2. A: Superselective angiography of the right SPA shows the infeasibility of further advancement of the microcatheter due to the severe tortuosity of the septal branches. B: Superselective angiography of the right IOA divided into two branches shows the $I_{1}$ route with a large diameter but acute angulation (white arrow) and the $I_{2}$ route with a relatively straight course (black arrow). C: The microcatheter was able to safely reach just before the fistulous point via the $I$ route. D: Onyx was injected into the microaneurysms in the feeding arteries as well as each fistulous compartment and proximal part of the drainage veins.

through the superior sagittal sinus (SSS). Three-dimensional DSA of the right ECA revealed the microaneurysms around the fistulous location where multiple feeding arteries converge. It was assumed that the microaneurysms located in the ethmoid sinus were the likely source of epistaxis (Fig. 1B-D).

We decided to perform endovascular treatment of transarterial embolization using the right ECA route because the microaneurysms causing epistaxis were located in the feeding arteries originating from the ECA just before the fistulous point. A 6-Fr sheath was placed at right femoral artery, and a 6-Fr guiding catheter (Envoy, Johnson \& Johnson) was introduced into the right ECA. Superselective angiography of each feeding artery was conducted to identify the focal angioarchitecture and the appropriate embolization position. The septal branches of the right SPA were so tortuous that further advancement of the microcatheter was not possible, so access to the fistulous point was attempted through the right IOA divided into two branches $\left(I_{1}\right.$ and $\left.I_{2}\right)$. Selective catheterization of the $I_{1}$ route with a large diameter but acute angulation was somewhat difficult, but the $I_{2}$ route with a relatively straight course allowed a safe approach to the location (Fig. 2A-C).

Through the $\mathrm{I}_{2}$ branch of the right IOA, a detachable tip microcatheter (Apollo, ev3 Neurovascular Inc.) was brought as close as possible to the optimal site using the wedged catheter technique. A liquid embolic agent (LEA) (Onyx 18, ev3 Neurovascular Inc.) was 
smoothly infused using the plug-creating technique and dispersed throughout the vascular networks. It obliterated not only each fistulous compartment and the proximal part of the drainage veins, but also the microaneurysms in the feeding arteries. The entire lesion disappeared after injection of $2.9 \mathrm{~mL}$ of Onyx (Fig. 2D).

Events such as distal migration of Onyx or entrapment of the microcatheter tip did not occur during the treatment. Postoperative DSA of the bilateral common carotid arteries showed complete occlusion of the fistula. Brain MRI performed a day after the procedure revealed no hemorrhage or infarction. Magnetic resonance angiography performed 3 months later demonstrated durable cure of the ethmoidal DAVF (Fig. 3). The patient had no neurological deficits or ophthalmological complications after the procedure. Epistaxis no longer appeared during the follow-up period of 16 months.

\section{Results of Literature Review}

We searched the literature using the PubMed database to examine the clinical symptoms of ethmoidal DAVFs and entered keywords such as "ethmoidal dural arteriovenous fistula," "anterior cranial fossa dural arteriovenous fistula," or "cribriform plate dural arteriovenous fistula." Search words such as "dural arteriovenous fistula," "arteriovenous malformation," or "cerebrovascular malformation" and "epistaxis" or "nasal bleed" were also entered to investigate cases dealing with lesions that cause epistaxis. Among the search results, reports of traumatic pseudoaneurysms or direct carotid cavernous fistulas (CCFs), non-IC cerebrovascular malformations, hereditary hemorrhagic telangiectasia, and pediatric dural sinus malformations were excluded.

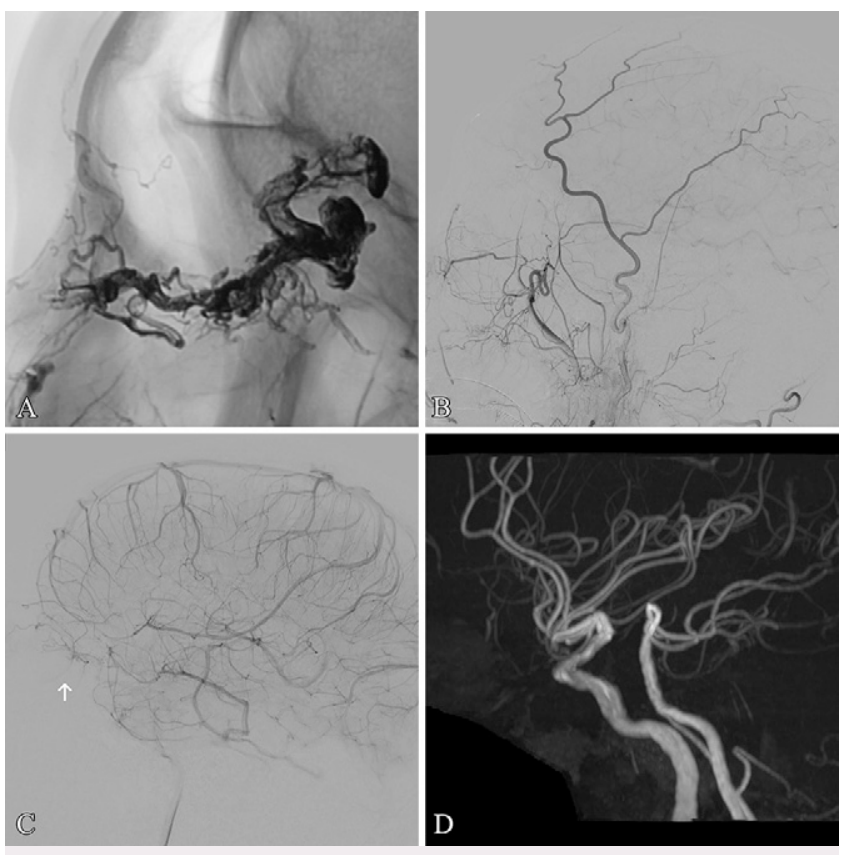

FIG. 3. A: The final cast of Onyx after the retrieval of the detachable tip microcatheter. B: Postoperative lateral angiography of the right ECA depicts no signs of remaining shunt flow. C: Postoperative lateral angiography of the left internal carotid artery shows the preservation of choroidal blush (arrow). D: Follow-up magnetic resonance angiography performed after 3 months demonstrates complete cure of the lesion.
Articles not available in the English language or articles in which the full text could not be retrieved were also excluded. All citations of the searched articles were then manually cross-referenced to identify other articles not found in the initial search.

A total of 411 patients in 109 articles had ethmoidal DAVFs supplied by ethmoidal arteries. Their symptoms were varied, including headache, seizure, visual impairment, and IC hemorrhage, and sometimes the DAVF was an incidental finding. ${ }^{5,6}$ Among the articles were four case reports of DAVFs causing epistaxis (1.0\%), and these are summarized in Table $1 .{ }^{10-13}$ Although different names were used, including dural arteriovenous malformation in the anterior cranial fossa, cribriform plate DAVF, and ophthalmic frontal DAVF, all 5 patients, including our case, had ethmoidal DAVFs, which were fed by two or more multiple feeding arteries, including the $A E A$, and drained directly into the frontal cortical vein or veins, eventually flowing through the SSS. The patients were all men, with a mean age of $57.2 \pm 11.9$ years (range 40-70 years), who showed a symptom of intractable epistaxis that was temporarily stopped by manual compression or nasal packing but continued to recur.

Başkaya et al. ${ }^{10}$ found an intranasal hyperintense signal on T1weighted MRI in an ethmoidal DAVF with epistaxis but did not mention what was the likely source. van Dijk et al. ${ }^{11}$ noted that the bleeding was associated with the fistulous network extending downward into the nasal cavity. Tripathi et al. ${ }^{12}$ found that the cause of epistaxis was likely the enlarged friable vessels originating from the ophthalmic artery $(\mathrm{OA})$ with a beaded appearance along its entire course. Sirakov et al. ${ }^{13}$ reported that venous aneurysmal-like dilatation in the ethmoid sinus contributed to the intranasal bleeding.

The first 3 patients were treated by coagulating the fistulous point of the feeding arteries and drainage vein or veins through bifrontal craniotomy. ${ }^{10-12}$ For removal of the source causing epistaxis, van Dijk et al. ${ }^{11}$ performed an additional transnasal endoscopic clipping and coagulation of the ECA branches including the SPA. Tripathi et al. ${ }^{12}$ concomitantly coagulated the basifrontal dural arteries, but there was significant blood loss from the anterior cranial fossa floor near the cribriform plate. Sirakov et al. ${ }^{13}$ conducted endovascular transarterial embolization using the $O A$ in the treatment of an ethmoidal DAVF without feeders from the ECA. In our case, the IOA supplying the microaneurysms was chosen as the treatment route for transarterial embolization. All 5 patients no longer had epistaxis, and the lesions regressed without recurrence.

\section{Discussion}

\section{Observations}

Anatomical Structure of Ethmoidal DAVFs

As in our case, the cause of most DAVFs is elusive and idiopathic, but it has been suggested that the etiology is acquired lesions caused by trauma, surgery, infection, and sinus thrombosis. ${ }^{14,15}$ The thrombosed dural venous sinus raises the internal venous pressure, resulting in an abnormal pressure gradient altering the direction of cerebral blood flow. ${ }^{14,16}$ Thus, the development of an arteriovenous shunt between the meningeal arteries of the sinus wall and the dural sinus or cortical veins eventually initiates a DAVF. In the enlargement of preexisting physiological shunts or de novo fistula development from neoangiogenesis, the ECA branches also evolve as additional feeders with potential upconversion. ${ }^{17}$

The AEA originating from the distal $O A$ in the orbit enters the ethmoid sinus through the orbital opening of the anterior ethmoid canal located in the medial orbital wall and passes through the 
TABLE 1. Summary of reporting cases of DAVFs causing epistaxis

\begin{tabular}{|c|c|c|c|c|c|c|c|c|}
\hline Authors \& Yr & Age (yrs)/Sex & Symptom & Diagnosis & Feeding Artery & Drainage Vein & Cognard & Treatment & Results \\
\hline $\begin{array}{l}\text { Sirakov et al., } \\
2018^{13}\end{array}$ & $40 / M$ & $\begin{array}{l}\text { Epistaxis, } \\
\text { headache, } \\
\text { vomiting }\end{array}$ & $\begin{array}{l}\text { Ethmoidal } \\
\text { DAVF } \\
\text { (accompanied } \\
\text { by SDH) }\end{array}$ & Both AEAs & $\begin{array}{c}\text { Frontal cortical } \\
\text { vein }\end{array}$ & Type IV & $\begin{array}{c}\text { Transarterial } \\
\text { embolization (It OA) }\end{array}$ & $\begin{array}{l}\text { Complete (no } \\
\text { recurrence) }\end{array}$ \\
\hline
\end{tabular}

$\mathrm{SDH}=$ subdural hematoma

anterior ethmoid foramen located at the lateral edge of the cribriform plate. ${ }^{1,18}$ This artery branches into the ethmoid sinus and nasal cavity before reaching the IC cavity and supplies the dura mater of the frontal convexity after reaching the IC cavity. ${ }^{18,19}$ The ethmoidal DAVF is developed through the AEA as a main dural arterial feeder; in addition, the extensive vascular networks sharing the ethmoid sinus and nasal cavity could be recruited as additional supplies via extracranial (EC)-EC and EC-IC anastomoses (Fig. 4).

The SPA is the terminal branch of the pterygopalatine segment of the internal maxillary artery (IMA), leaving the pterygopalatine fossa and passing through the sphenopalatine foramen. ${ }^{20}$ It

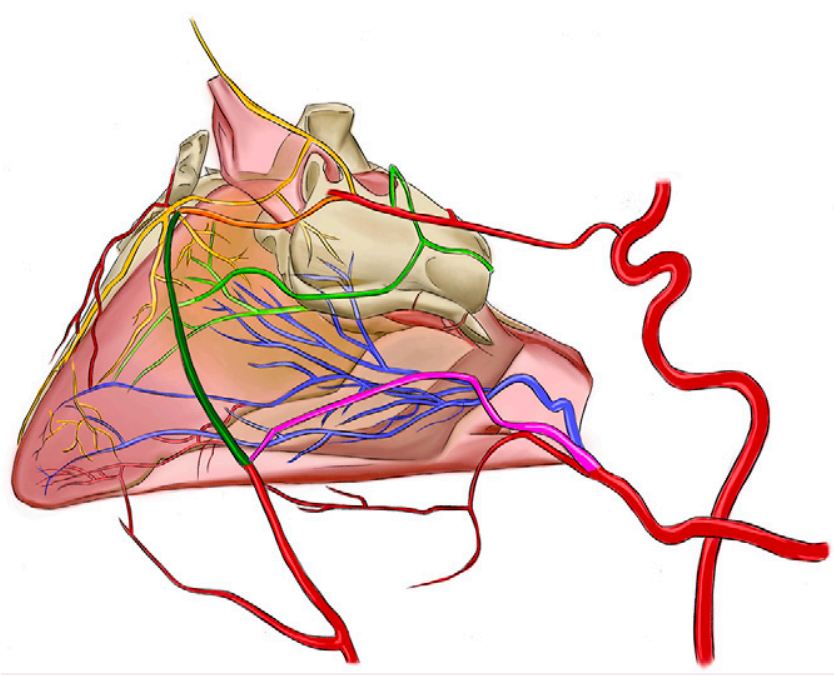

FIG. 4. The extensive EC-EC and EC-IC anastomoses sharing the ethmoid sinus and nasal cavity. AA (dark green), AEA (yellow), dorsal nasal artery (orange), IOA (pink), posterior ethmoidal artery (light green), and SPA (blue). divides into 2 to 4 septal and nasal branches after entering the nasal cavity $^{21}$ and anastomoses with the AEA and other arteries to constitute Kiesselbach's plexus, which is known to cause epistaxis as well. ${ }^{21,22}$ The IOA is also a pterygopalatine IMA segment, which enters the orbital cavity via the inferior orbital fissure, runs anteriorly along the infraorbital groove, and emerges through the infraorbital foramen onto the face. ${ }^{23}$ It then travels toward the nose and medial angle of the orbit, forming the collateral pathways with the $A A$, another branch of facial artery, and the dorsal nasal artery of the $O A .{ }^{20}$ In practice, the SPA, ${ }^{24}{ }^{2} \mathrm{OA},{ }^{6} \mathrm{AA},{ }^{25}$ middle meningeal artery (MMA), ${ }^{26}$ and superficial temporal artery ${ }^{27}$ are well-known as arterial feeders of ethmoidal DAVFs originating from the ECAs.

\section{Epistaxis Associated With Ethmoidal DAVFs}

Epistaxis due to IC lesions has been reported occasionally in skull base fractures, traumatic pseudoaneurysms, and direct CCFs, but has rarely been reported in DAVFs. ${ }^{22}$ The reported cases of epistaxis in ethmoidal DAVFs were only 1\% (4/411 patients) in our PubMed literature search, and in our case, we also did not recognize the necessity of IC evaluation until headache was experienced by the patient. The 5 reviewed patients, including ours, with ethmoidal DAVFs causing epistaxis showed microaneurysms associated with a feeding artery, enlarged friable vessels with a beaded appearance, and aneurysmal-like dilatation of a drainage vein in the ethmoid sinus and nasal cavity, which were suggested as likely sources of epistaxis.

Considering that the clinical symptoms of general DAVFs occur frequently in the drainage vein under high pressure, it seems that epistaxis is not common in the ethmoidal DAVF, unlike the pulsatile tinnitus of the transverse-sigmoid sinus DAVF or the ophthalmological manifestations of the cavernous sinus DAVF. And although it is extremely rare, because the ethmoidal DAVF carries a high potential risk of IC hemorrhage and the onset of new symptoms in DAVFs may be a precursor to aggressive upconversion, ${ }^{17}$ it should 
be included in the differential diagnosis of recurrent epistaxis for early diagnosis and prompt treatment.

\section{The ECA Route for Treatment of Ethmoidal DAVFs}

The treatment of ethmoidal DAVFs has traditionally favored surgical obliteration with a high success rate. ${ }^{7,8}$ In particular, minisupraorbital craniotomy through transpalpebral incision refined as a less invasive surgery is currently being attempted in the treatment of ethmoidal DAVFs. ${ }^{28,29}$ We think that it is a good alternative surgical technique to improve aesthetic faults in limited cases as compared with traditional bicoronal craniotomy. However, there might still be inherent surgical risks such as frontal sinus exposure, cerebrospinal fluid leakage, and facial nerve injury.

The preference for endovascular embolization in recent years is increasing considerably, along with more advances in endovascular technology and devices. ${ }^{8,9}$ Transarterial embolization via the OA route is commonly used in ethmoidal DAVFs, ${ }^{30,31}$ but the risk of central retinal artery occlusion by reflux of embolic agents always makes the operator be concerned. To address this issue, a dual-lumen microballoon catheter with excellent navigability in the small and tortuous feeders and reduced risk of LEA reflux has recently been introduced. $^{32,33}$ Unfortunately, the product is not yet available worldwide, including our country. A new tool such as a microballoon catheter is expected, perhaps in the near future, to treat ethmoidal DAVFs more safely. Transvenous embolization can also be an effective alternative for the treatment of ethmoidal DAVFs like other types of DAVFs. ${ }^{34,35}$ However, its use is limited to the cases of a well-developed anterior third of the SSS and short cortical venous pathways. Moreover, it carries the potential risk of venous perforation when the microcatheter or microwire is advanced along the tortuous cortical veins with ectasia or when the microcatheter is retrieved after injecting the LEA.

Transarterial embolization via the ECA route has now become a feasible alternative thanks to advances in distal access microcatheters and LEAs such as Onyx. This approach has the potential to improve the success rate of endovascular embolization because of the lower risk of visual complications and a longer arterial feeder to strengthen the reflux plug. Attempts to treat ethmoidal DAVFs via the MMA have also been published recently. ${ }^{26}$ However, because IMA branches such as the SPA, IOA, MMA, AA, and superficial temporal artery also form a dangerous EC-IC anastomosis with the $\mathrm{OA}$ branches in the orbital region, care should be taken to avoid embolic stroke by retrograde filling. ${ }^{36}$

In our case, first treating ethmoidal DAVFs with multiple arterial feeders via surgical obliteration may be somewhat risky because there could be significant blood loss from numerous vascular channels in the anterior skull base. Transarterial embolization using the $\mathrm{OA}$ as the access route was considered to be risky for injecting an embolizing agent because of its long and narrow path from the opposite side. Transvenous embolization was also thought to be inappropriate for access through the cortical veins with tortuous ectasia in the less-developed anterior third of the SSS, and it was also not optimal considering that the bleeding source was located on the arterial side.

Specifically, the special reason for using the ECA route in our case was that the microaneurysms causing epistaxis were located in the feeding arteries originating from the ECA just before the fistulous point, so it was expected that the bleeding source could be removed more effectively. We successfully treated the fistula by transarterial Onyx embolization using the very rare ECA route of the IOA, which is the first reported case to the best of our knowledge. Therefore, because any ECA route can be an alternative if the microcatheter is accessible distally, it is important to determine an effective route according to the anatomical treatment target based on an understanding of the angioarchitecture and hemodynamics of ethmoidal DAVFs.

\section{Lessons}

Although extremely rare, ethmoidal DAVFs should be included in the differential diagnosis of recurrent epistaxis. Ethmoidal DAVFs with bleeding factors in the ethmoid sinus and nasal cavity may cause epistaxis. It is important to properly diagnose and treat ethmoidal DAVFs presenting with epistaxis on the basis of a comprehensive anatomical understanding of extensive EC-EC and EC-IC anastomoses.

\section{References}

1. Awad IA, Little JR, Akarawi WP, Ahl J. Intracranial dural arteriovenous malformations: factors predisposing to an aggressive neurological course. J Neurosurg. 1990;72(6):839-850.

2. Halbach VV, Higashida RT, Hieshima GB, et al. Dural arteriovenous fistulas supplied by ethmoidal arteries. Neurosurgery. 1990;26(5): 816-823.

3. Lawton MT, Chun J, Wilson CB, Halbach VV. Ethmoidal dural arteriovenous fistulae: an assessment of surgical and endovascular management. Neurosurgery. 1999;45(4):805-811.

4. Agid R, Terbrugge K, Rodesch G, et al. Management strategies for anterior cranial fossa (ethmoidal) dural arteriovenous fistulas with an emphasis on endovascular treatment. J Neurosurg. 2009;110(1): 79-84.

5. Dabus G, Kan P, Diaz C, et al. Endovascular treatment of anterior cranial fossa dural arteriovenous fistula: a multicenter series. Neuroradiology. 2021;63(2):259-266.

6. Meneghelli $P$, Pasqualin A, Lanterna LA, et al. Surgical treatment of anterior cranial fossa dural arterio-venous fistulas (DAVFs): a twocentre experience. Acta Neurochir (Wien). 2017;159(5):823-830.

7. Giannopoulos S, Texakalidis P, Mohammad Alkhataybeh RA, et al. Treatment of ethmoidal dural arteriovenous fistulas: a meta-analysis comparing endovascular versus surgical treatment. World Neurosurg. 2019;128:593-599.e1.

8. Cannizzaro D, Peschillo S, Cenzato M, et al. Endovascular and surgical approaches of ethmoidal dural fistulas: a multicenter experience and a literature review. Neurosurg Rev. 2018;41(2):391-398.

9. Gross BA, Moon K, Kalani MY, et al. Clinical and anatomic insights from a series of ethmoidal dural arteriovenous fistulas at Barrow Neurological Institute. World Neurosurg. 2016;93:94-99.

10. Başkaya MK, Suzuki Y, Seki Y, et al. Dural arteriovenous malformations in the anterior cranial fossa. Acta Neurochir (Wien). 1994;129( 3-4):146-151.

11. van Dijk JM, Korsten-Meijer AG, Mazuri A. Epistaxis caused by a dural AV-fistula at the cribriform plate. Laryngoscope. 2014;124(11): 2476-2477.

12. Tripathi M, Kamal Ahuja C, Gupta A, et al. Recurrent epistaxis due to cribriform plate dural arteriovenous fistula: are they related? Should the treatment be from venous, pial or arterial side? $\mathrm{Br} \mathrm{J}$ Neurosurg. Published online October 13, 2018. doi:10.1080/ 02688697.2018 .1524077

13. Sirakov S, Sirakov A, Hristov H, Ninov K. Successful endovascular treatment of ruptured bilateral ophthalmic frontal dural arteriovenous fistula. Radiol Case Rep. 2018;13(5):1036-1041.

14. Chung SJ, Kim JS, Kim JC, et al. Intracranial dural arteriovenous fistulas: analysis of 60 patients. Cerebrovasc Dis. 2002;13(2):79-88. 
15. Sun LL, Tang WX, Liu L, et al. Dural arteriovenous fistula disguised as cerebral venous sinus thrombosis. J Zhejiang Univ Sci B. 2017; 18(8):733-736.

16. Gandhi D, Chen J, Pearl M, et al. Intracranial dural arteriovenous fistulas: classification, imaging findings, and treatment. AJNR Am J Neuroradiol. 2012;33(6):1007-1013.

17. Reynolds MR, Lanzino G, Zipfel GJ. Intracranial dural arteriovenous fistulae. Stroke. 2017:48(5):1424-1431.

18. White DV, Sincoff EH, Abdulrauf SI. Anterior ethmoidal artery: microsurgical anatomy and technical considerations. Neurosurgery. 2005;56(2 suppl):406-410.

19. Pandolfo I, Vinci S, Salamone I, et al. Evaluation of the anterior ethmoidal artery by $3 \mathrm{D}$ dual volume rotational digital subtraction angiography and native multidetector CT with multiplanar reformations. Initial findings. Eur Radiol. 2007;17(6):1584-1590.

20. Tanoue $\mathrm{S}$, Kiyosue $\mathrm{H}$, Mori $\mathrm{H}$, et al. Maxillary artery: functional and imaging anatomy for safe and effective transcatheter treatment. Radiographics. 2013;33(7):e209-e224.

21. Mostafa BE, Elsamny TA, Youssef TA, et al. Arterial blood supply of the nose: an angiographic study. ORL J Otorhinolaryngol Relat Spec. 2018;80(5-6):238-247.

22. Willems PW, Farb RI, Agid R. Endovascular treatment of epistaxis. AJNR Am J Neuroradiol. 2009;30(9):1637-1645.

23. Allen WE III, Kier EL, Rothman SL. The maxillary artery: normal arteriographic anatomy. Am J Roentgenol Radium Ther Nucl Med. 1973;118(3):517-527.

24. Hashiguchi $A$, Mimata $\mathrm{C}$, Ichimura $\mathrm{H}$, et al. Venous aneurysm development associated with a dural arteriovenous fistula of the anterior cranial fossa with devastating hemorrhage-case report. Neurol Med Chir (Tokyo). 2007;47(2):70-73.

25. Ishihara $\mathrm{H}$, Ishihara $\mathrm{S}$, Neki $\mathrm{H}$, et al. Dural arteriovenous fistula of the anterior cranial fossa with carotid artery stenosis treated by simultaneous transarterial embolization and carotid artery stenting. Neurol Med Chir (Tokyo). 2010;50(11):995-997.

26. Deng JP, Li J, Zhang T, et al. Embolization of dural arteriovenous fistula of the anterior cranial fossa through the middle meningeal artery with Onyx. Clin Neurol Neurosurg. 2014;117:1-5.

27. Chen Z, Miao H, Feng H, Zhu G. Prominent forehead scalp arteries a diagnostic clue to unruptured anterior cranial fossa dural arteriovenous fistula. Arch Neurol. 2011;68(6):824-825.

28. O'Connor KP, Bohnstedt BN. Left anterior cranial fossa dural arteriovenous fistula ligation using a supra-orbital (eyebrow) craniotomy. Neurosurg Focus. 2019;46(suppl 2):V3.

29. Delavari N, Staffenberg D, Riina H. Transpalpebral Incision for Resection of an Ethmoidal Dural Arteriovenous Fistula: 2-Dimensional
Operative Video. Oper Neurosurg (Hagerstown). Published online July 16, 2020. doi:10.1093/ons/opaa213

30. Piergallini L, Tardieu M, Cagnazzo F, et al. Anterior cranial fossa dural arteriovenous fistula: transarterial embolization from the ophthalmic artery as first-line treatment. J Neuroradiol. Published online June 20, 2019. doi:10.1016/j.neurad.2019.05.009

31. Li $Q$, Fang YB, Huang $Q H$, et al. Transarterial embolization of dural arteriovenous fistulas of the anterior cranial fossa with Onyx. J Clin Neurosci. 2013;20(2):287-291.

32. Vollherbst DF, Chapot R, Wallocha M, et al. First clinical multicenter experience with the new Scepter Mini microballoon catheter. J Neurointerv Surg. 2020;13(3):261-266.

33. Pulli B, Sussman ES, Mayercik V, et al. Initial experience with the Scepter Mini dual-lumen balloon for transophthalmic artery embolization of anterior cranial fossa dural arteriovenous fistulae. J Neurointerv Surg. 2020;12(11):1132-1136.

34. Spiotta AM, Hawk H, Kellogg RT, et al. Transfemoral venous approach for Onyx embolization of anterior fossa dural arteriovenous fistulae. J Neurointerv Surg. 2014;6(3):195-199.

35. Limbucci N, Leone G, Nappini S, et al. Transvenous embolization of ethmoidal dural arteriovenous fistulas: case series and review of the literature. World Neurosurg. 2018;110:e786-e793.

36. Geibprasert S, Pongpech S, Armstrong D, Krings T. Dangerous extracranial-intracranial anastomoses and supply to the cranial nerves: vessels the neurointerventionalist needs to know. AJNR Am J Neuroradiol. 2009;30(8):1459-1468.

\section{Disclosures}

The authors report no conflict of interest concerning the materials or methods used in this study or the findings specified in this paper.

\section{Author Contributions}

Conception and design: Lee, MY Kwon. Acquisition of data: MY Kwon, Kim. Analysis and interpretation of data: Lee, MY Kwon. Drafting the article: MY Kwon. Critically revising the article: Lee. Reviewed submitted version of manuscript: SM Kwon. Approved the final version of the manuscript on behalf of all authors: Lee. Statistical analysis: MY Kwon.

\section{Correspondence}

Chang-Young Lee: Keimyung University Dongsan Hospital, Keimyung University School of Medicine, Daegu, Republic of Korea. nslcy@dsmc. or.kr. 